Review

\title{
Friction Stir Welding/Processing of High Entropy Alloys (HEAs)
}

\author{
Akshansh Mishra \\ Department of Mechanical Engineering, Politecnico Di Milano, Italy \\ akshansh.frictionwelding@gmail.com
}

Received: 19.09.2020; Accepted: 10.12.2020

\begin{abstract}
The composition of High Entropy Alloys is quite different from the existing classical engineering alloys because in near equiatomic ratios they contain multiple principal alloying elements. Design and development of high entropy alloys is very important to overcome the shortcomings of conventionally used alloys in applications where operating conditions of temperature and loading are extreme. High entropy alloys generally find applications in compressor blades of an aerospace engine, energy, and transportation industries due to its low density and high strength. In order to enhance the application of high entropy alloys, the proper selection of a feasible welding process is very important. It has been observed that when high entropy alloys are subjected to the welding process other than the Friction Stir Welding process then it will result in reduced overall strength and lower hardness in the fusion zone and heat-affected zone. In this recent paper, the application of Friction Stir Welding for joining the high entropy alloys and also using Friction Stir Processing for improving the mechanical and microstructure properties of high entropy alloys are discussed.
\end{abstract}

$\underline{\text { Keywords: High Entropy Alloys; Friction Stir Welding; Friction Stir Processing }}$

\section{What are High Entropy Alloys (HEAs)?}

High entropy alloys (HEAs) are new generation alloys which consists of a more than one principal element in a multi-component system. HEAs are also known as multi-principal element alloys (MPEAs) or complex concentrated alloys (CCAs). In 2004, the concept of multi-principal element alloys (MPEAs) and high entropy alloys (HEAs) was first proposed by Professor Ye Junwei [1,2]. Each HEA is a new alloy base, since each HEA can be modified by minor elemental additions as for current element-based alloys. HEAs give a vast number of new alloy bases [3]. The number of HEA systems (unique combination of elements, without specifying composition) is:

$$
\mathrm{C}\left(\begin{array}{l}
n \\
r
\end{array}\right)=\frac{n !}{r !(n-r) !}
$$

where: $\mathrm{n}$ represents the number of elements in the palette from which $\mathrm{r}$ principal alloy elements are being selected. Researchers involved in alloy development previously focused on the corners of a phase diagram to develop a conventional alloy, which occupy only a small portion of the design space, as depicted in the figure 1. However, with the recent development of HEAs, the focus has been shifted to the central region [4].

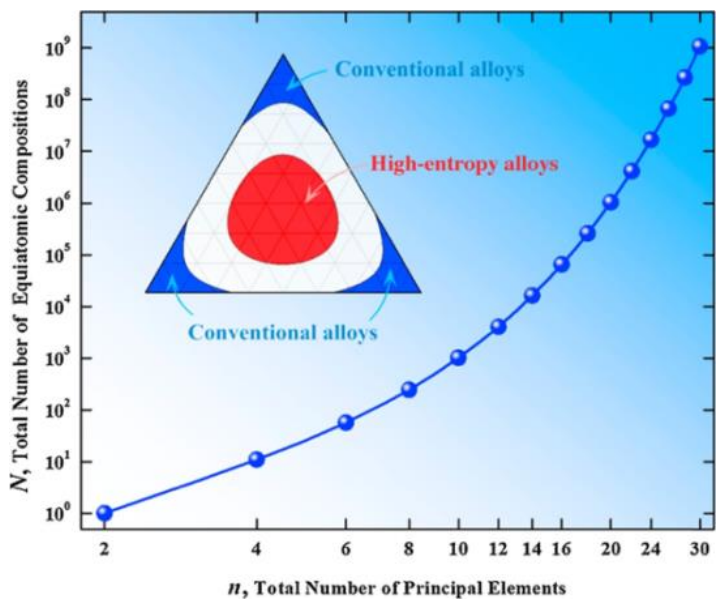

Fig. 1. The variation in the total number of equiatomic compositions with the total number of principal elements. The inset illustrates the difference between the design of conventional alloys and high-entropy alloys on a ternary plot [4] 
High entropy alloys (HEAs) are prepared with at least five metallic components and every one of these components has a molar atomic concentration which ranges between 5 and 35\%. High Entropy Alloys shows good ductility, they have excellent work hardenability and high-temperature oxidation resistance. HEAs also exhibit excellent attractive magnetic properties, have high wear resistance and shows good erosion opposition. Fabrication method of HEAs can be classified into three major types i.e. Liquid mixing, solid mixing and gaseous mixing. The liquid mixing includes arc melting, electric resistance melting, inductive

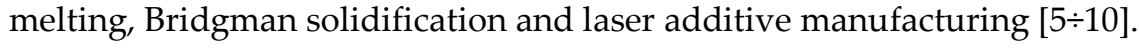

\section{Designing High Entropy Alloys}

The components in the blend need not be equivalent or near equal while designing High Entropy Alloys (HEAs). By having not less than five elements in the composition, higher configurational entropy is achieved. Configurational entropy means the number of recognizable ways the atoms can be arranged on the lattice sites. The main reason is an increment in the number of components which further increases the mixing entropy and results with the best explanation for the high entropy effect which is an important factor to the designing of high entropy alloys.

$$
\begin{gathered}
\mathrm{N}_{\text {major elements }} \geq 5 \text { at. } \% \leq 35 \text { at } \% \\
\mathrm{~N}_{\text {minor elements }} \geq 0 \geq 5 \text { at } \%
\end{gathered}
$$

The system is said to be at equilibrium when the Gibbs Free Energy is at its base.

$$
\Delta \mathrm{G}_{\text {mix }}=\Delta \mathrm{H}_{\text {mix }}-\mathrm{T} \Delta \mathrm{S}
$$

where the enthalpy of mixing is the $\Delta \mathrm{Hmix}, \Delta \mathrm{Smix}$ is the entropy of mixing and $\mathrm{T}$ is the temperature.

The molar configuration entropy design gives better outcomes of forming a multi-element solid solution phase through statistical thermodynamics with the help of the Boltzmann hypothesis on the entropy of mixing.

$$
\Delta \mathrm{S}_{\text {conf }}=-\mathrm{Kln} \mathrm{w}=-\mathrm{R} \ln \frac{1}{\mathrm{n}}=-\mathrm{R} \operatorname{lnn} \Delta \mathrm{S}_{\text {mix }}=\mathrm{R} \ln (\mathrm{n})
$$

where:

$\Delta \mathrm{S}_{\text {conf }}$ is the molar concentration,

$\mathrm{K}$ is the Boltzmann constant, $\mathrm{w}$ is the thermodynamic probability,

$\mathrm{R}$ is the gas constant $(8.134 \mathrm{~J} / \mathrm{kmol})$

$\mathrm{n}$ is the number of elements in the composition.

\section{Applications of High Entropy Alloys}

The entropic alloys can be classified into four types i.e. high entropy alloys, medium entropy alloys, low entropy alloys and pure metal as shown in the figure 2. High entropy alloys outperforms conventional material in terms of low temperature applications.

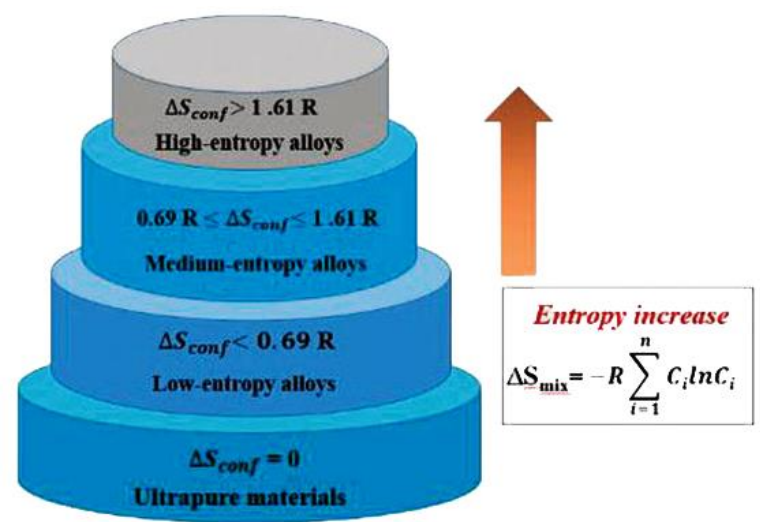

Fig. 2. Classification of entropic alloy [18]

High Entropy alloys find application in cryogenic operations [18]. As a low temperature material they can be used in civil engineering domain, superconducting fields and in aerospace industries. Geanta et al. [19] carried out testing and characterization of High-Entropy Alloys from AlCrFeCoNi System for various military applications. Microstructure study showed that at molten condition, microstructure of high entropy 
alloys had a frozen appearance as shown in the figure 3. Impact testing behavior showed that high entropy alloy is the best option for ballistic packages resistant at high velocity penetration impacts as shown in figure 4.

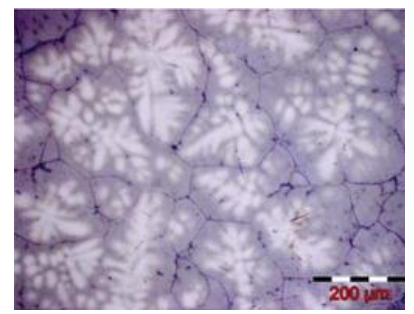

HEA 1

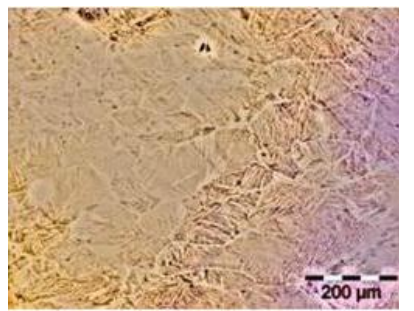

HEA 5

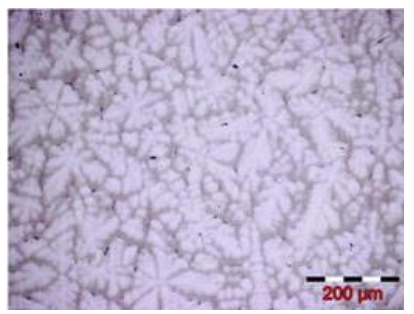

HEA 2

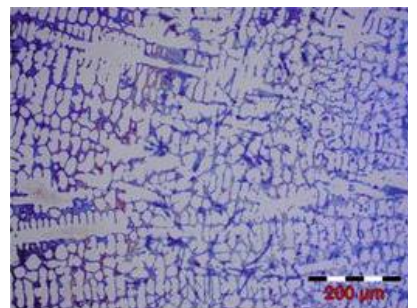

HEA 6

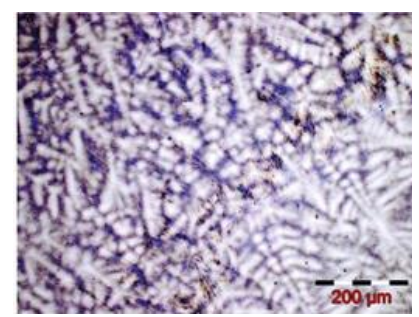

HEA 3

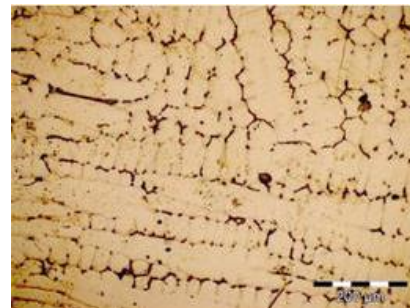

HEA 7

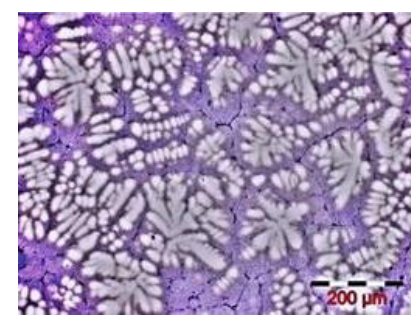

HEA 4

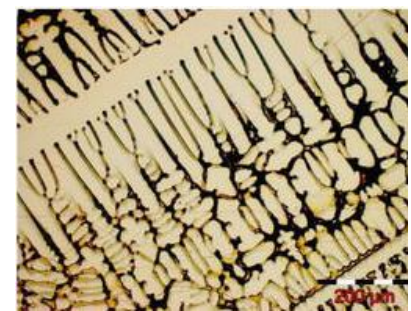

HEA 8

Fig. 3. Microstructure of an experimental as-cast AlCrxFeCoNi alloys [19]

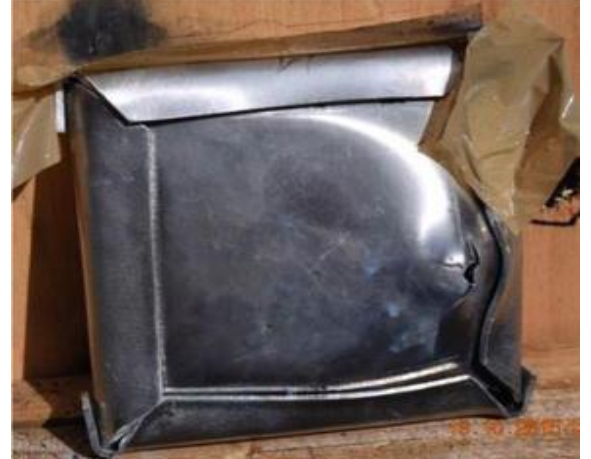

(a)

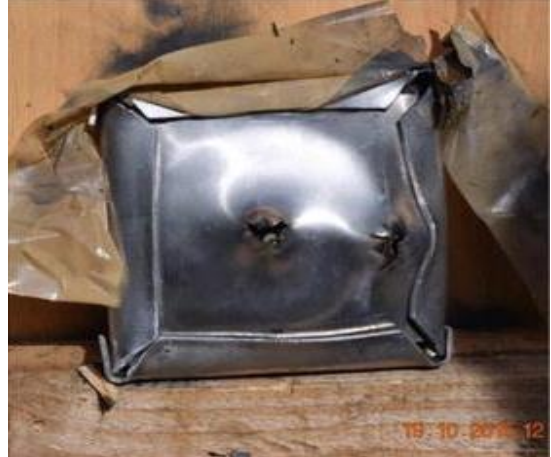

(b)

Fig. 4. HEA-steel ballistic package during dynamic tests (a) after the first firing and (b) after the second firing [19]

High Entropy Alloys also find applications in micro and nano-joining techniques. High Entropy Alloys can be easily fabricated into rods and wires due to high ductility and further can be used as a filler material for a joining purpose. High Entropy Alloy filler material ensures a safe joint because it inhibits the formation of intermetallic compounds in the joint [20].

\section{Joining High Entropy Alloys by Friction Stir Welding Process}

Friction Stir Welding is a solid-state joining process invented by The Welding Institute (TWI), UK in 1991. Experimental Setup of the Friction Stir Welding process is shown in the figure 5. Friction Stir Welding process setup consists of the backing plate on which the alloys to be welded are placed, a tool which is harder than the base metal alloys to be joined.

Tool traverse speed, rotational speed, axial force and tool tilt angle are important parameters which governs the mechanical and microstructure properties of Friction Stir Welded joints. Unlike other conventional welding process Friction Stir Welding process joins the two metal alloy plates by plasticizing mechanism rather melting them. So this working mechanism avoids the formation of various defects occurring in conventional welded joints and hence it results with a good quality welded joint.

In previous research papers, researchers have mainly focused on the state of art on the Friction Stir Welded Aluminum, Magnesium and steel alloys. So, there is limited available state of art on Friction Stir Welded High Entropy Alloys (HEAs).

Park et al. [12] studied about the influence of the initial grain size on the plastic deformation and tunnel defects that occurred during friction stir welding of $\mathrm{CoCrFeMnNi} \mathrm{high} \mathrm{entropy} \mathrm{alloys} \mathrm{(HEAs).} \mathrm{The} \mathrm{results}$ showed that the rolled and cast High Entropy Alloys (HEAs) had a grain size of 2.8 and $308 \mu \mathrm{m}$, but after friction stir welding, the cast HEA weld had a grain size of $1.8 \mu \mathrm{m}$, which was coarser than that of 
the rolled HEA weld $(1.4 \mu \mathrm{m})$. Jo et al. [13] butt welded thin plates of CrMnFeCoNi.with the help of Friction Stir Welding process.

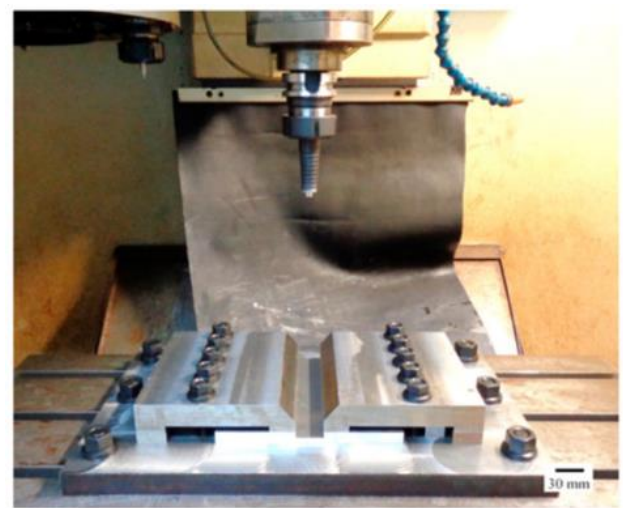

Fig. 5. Experimental setup of friction stir welding on a Computer Numerical Control (CNC) machine [11]

It was observed that when compared with the base metal, Friction Stir Welding process refined the grain size in the weld region by a factor of approximately 14. Nene et al. [14] investigated a strong and ductile nonequi-atomic high entropy alloy obtained after friction stir processing method (FSP). Figures 1a-c depicts electron back scattered diffraction (EBSD) maps for the as-homogenized and 350 and 650 rotations per minute (RPM) treated Friction Stir Processed samples. It is observed that there is a drastic reduction in average grain size from $\sim 100 \mu \mathrm{m}$ to 6.5 and $5.2 \mu \mathrm{m}$. Friction Stir Processing is a high temperature, severe plastic deformation process so it also changed the fraction of f.c.c. $\gamma$ and h.c.p. $\varepsilon$-phases in the microstructure by maintaining the chemical homogeneity. Figures $6 \mathrm{~d}_{1}$ and $6 \mathrm{~d}_{2}$ show the EDS analysis results for a 350 RPM specimen which depicts average compositions of the constituent elements of the dual phase (DP)high entropy alloy which further suggests homogeneity in the obtained microstructure. Phase changes that have occurred with Friction Stir Processing which is indicated by the variation in peak intensities for f.c.c. $\gamma$ and h.c.p. $\varepsilon$-phases as a function of Friction Stir Processing tool rotation rates is shown in figure 6e. The fraction of high-angle grain boundaries (HAGBs), as indicated by blue lines, it is observed that it decreases in comparison to the as-homogenized material due to severe plastic deformation during Friction Stir Processing shown by figure $6 \mathrm{f}$.
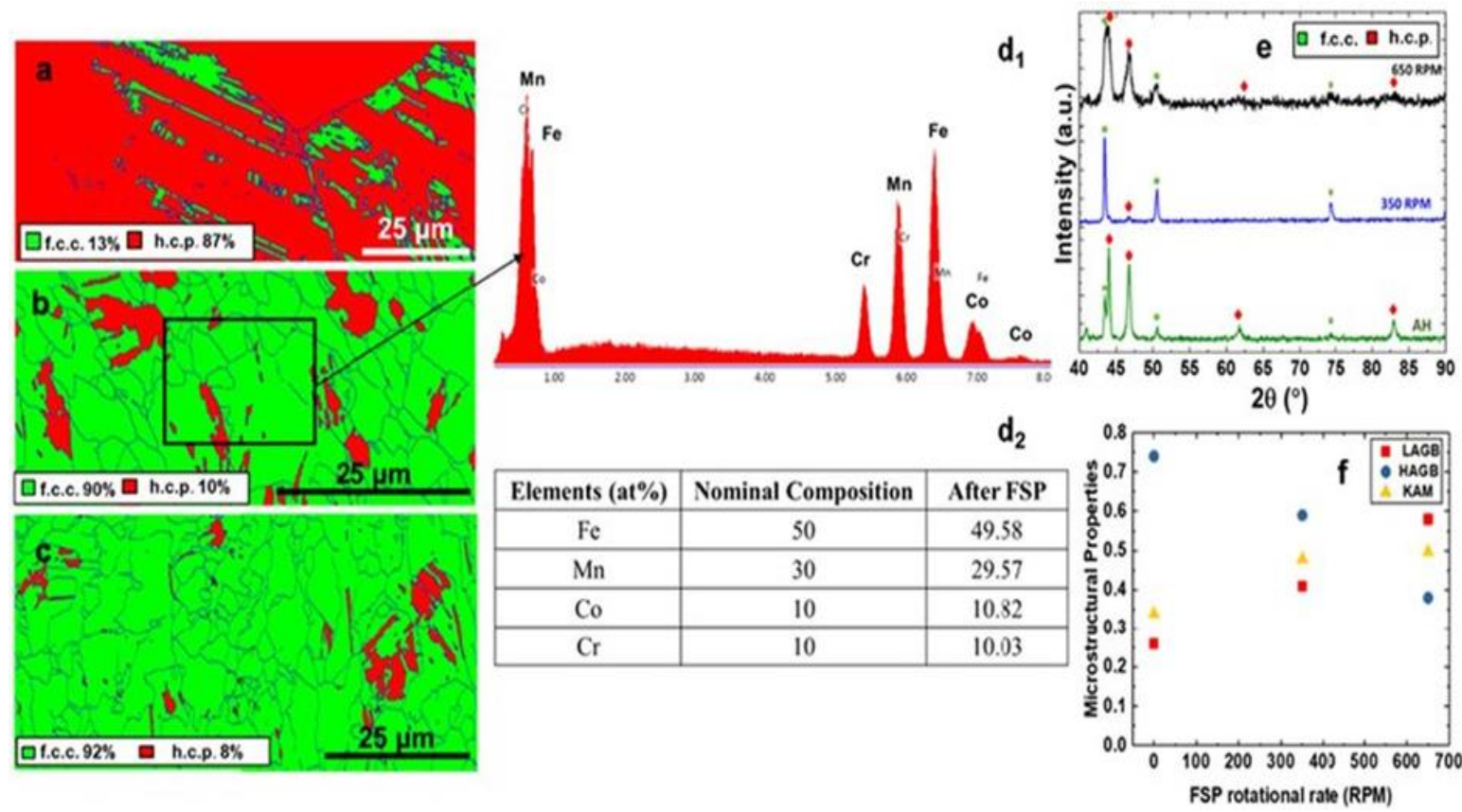

Fig. 6. $(\mathrm{a}-\mathrm{c})$ Phase maps for the material in the as-homogenized condition; after additional 350, and after 650 RPM processing, $\left(\mathrm{d}_{1}-\mathrm{d}_{2}\right)$ corresponding EDS results for 350 RPM processed sample, (e) corresponding XRD results for the as-homogenized and FSP samples, (f) microstructural properties including the fraction of high angle grain boundaries, low angle grain boundaries, and kernel average misorientation values after FSP. AH: as-homogenized; FSP: friction stir processing; RPM: rotations per minute; LAGB: low angle grain boundary; HAGB: high angle grain boundary [14] 
Figure 7 shows the stress-strain behaviour of as-homogenized and FSP samples deformed at room temperature.

Komarasamy et al. [15] studied about the effect of microstructure on the deformation mechanism of Friction Stir-Processed Al0.1CoCrFeNi High Entropy Alloy. The results showed that the Friction Stir Processed region exhibit an immense variation in the microstructure due to slow rate of atomic diffusion in high entropy alloys (HEAs). Microstructural evolution, grain growth and dynamic recrystallization during Friction Stir Processing is controlled by strain rate, strain and temperature experienced by that local region as shown in Figures 8 and 9.

Zhu et al. [16] friction stir welded CoCrFeNiAl0.3 high entropy alloy. It was observed that there was no formation of defects. Shaysultanov et al. [17] friction stir welded carbon-doped CoCrFeNiMn high-entropy alloy. The observation showed that friction stir welding resulted in a decrease in grain size from $9.2 \mu \mathrm{m}$ to $4.6 \mu \mathrm{m}$.
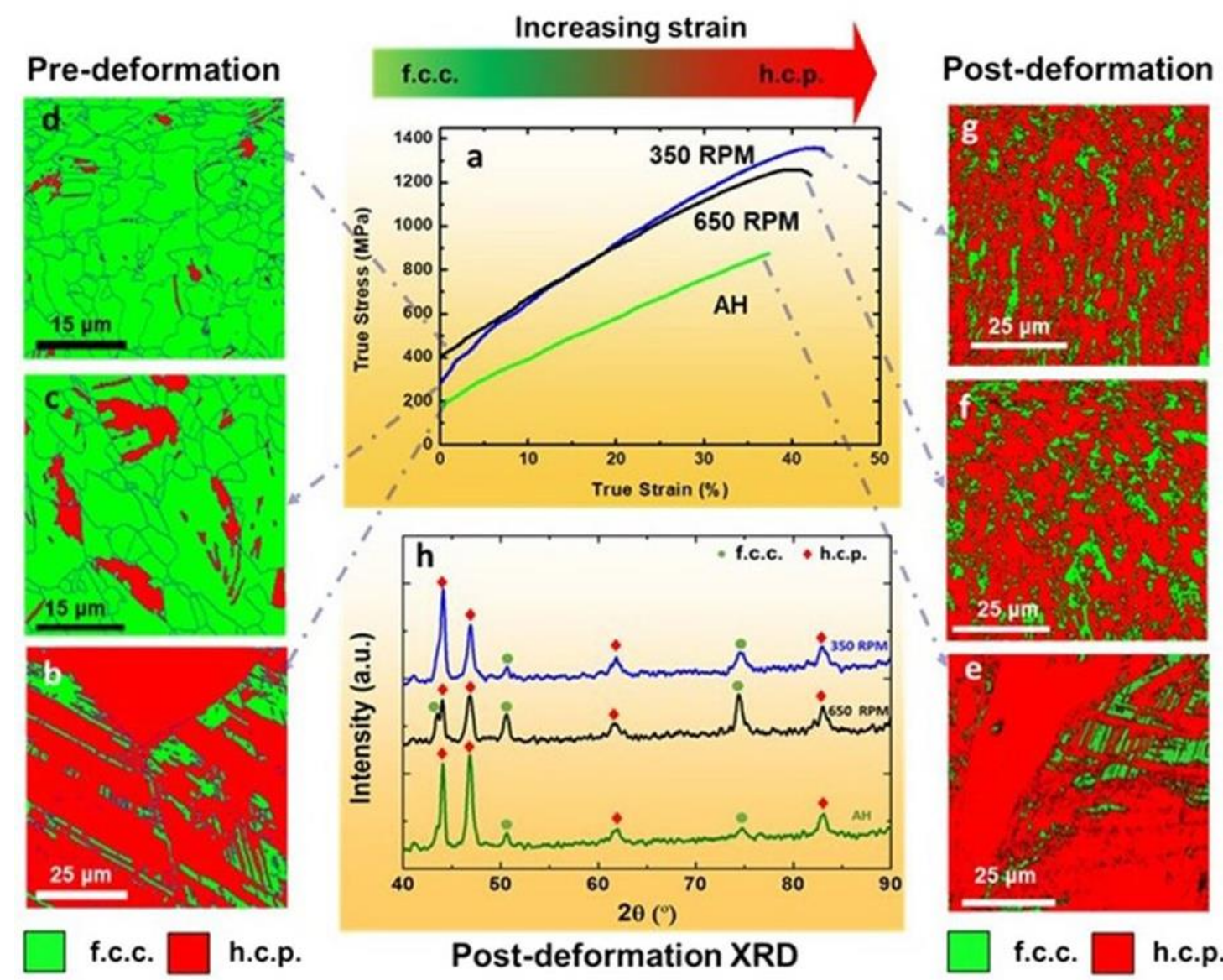

Fig. 7. (a) True stress-true strain curves for the as-homogenized and FSP samples deformed at room temperature at an initial strain rate of 10-3 s-1, (b-d) EBSD maps showing f.c.c. $\gamma$ - and h.c.p. $\varepsilon$-phase fractions prior to tensile deformation and, (e-h) EBSD maps and corresponding XRD patterns showing f.c.c. $\gamma$ - and h.c.p. $\varepsilon$-phase fractions after tensile deformation. AH: as-homogenized; RPM: rotations per minute [14]

\section{Conclusions}

High-entropy alloys (HEAs) are a special class of alloys that were designed to obtain a single-phase massive solid solution which is free from any secondary phases. Recent research shows that the Friction Stir Welding process results in higher hardness in the fusion zone and nurture the strength of the welded joints subjected under tensile load. This research shows that the HEA can be joined efficiently with the help of Friction Stir Welding process and also any types of defect formation can be avoided by controlling the input parameters like Tool Rotational Speed and Traverse speed. It is also observed that Friction Stir Welding process results in decrease in grain size and also cause grain refinement. It can also be concluded that Friction Stir Processing can be used for grain refinement and also for enhancement of strength and ductility of High Entropy Alloys. 

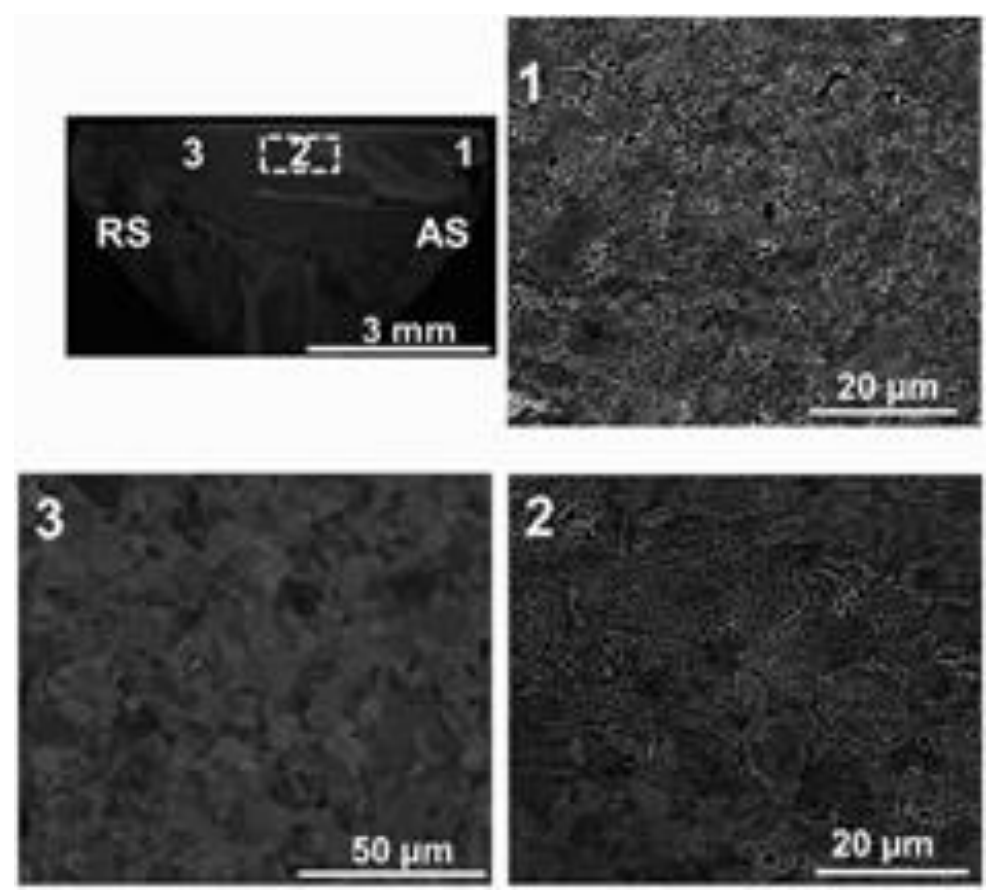

Fig. 8. SEM micrographs taken at various locations in the friction stir-processed region. The locations are marked along with the location of cross-section of the mini-tensile sample gage on the macro view of the processed region [15]
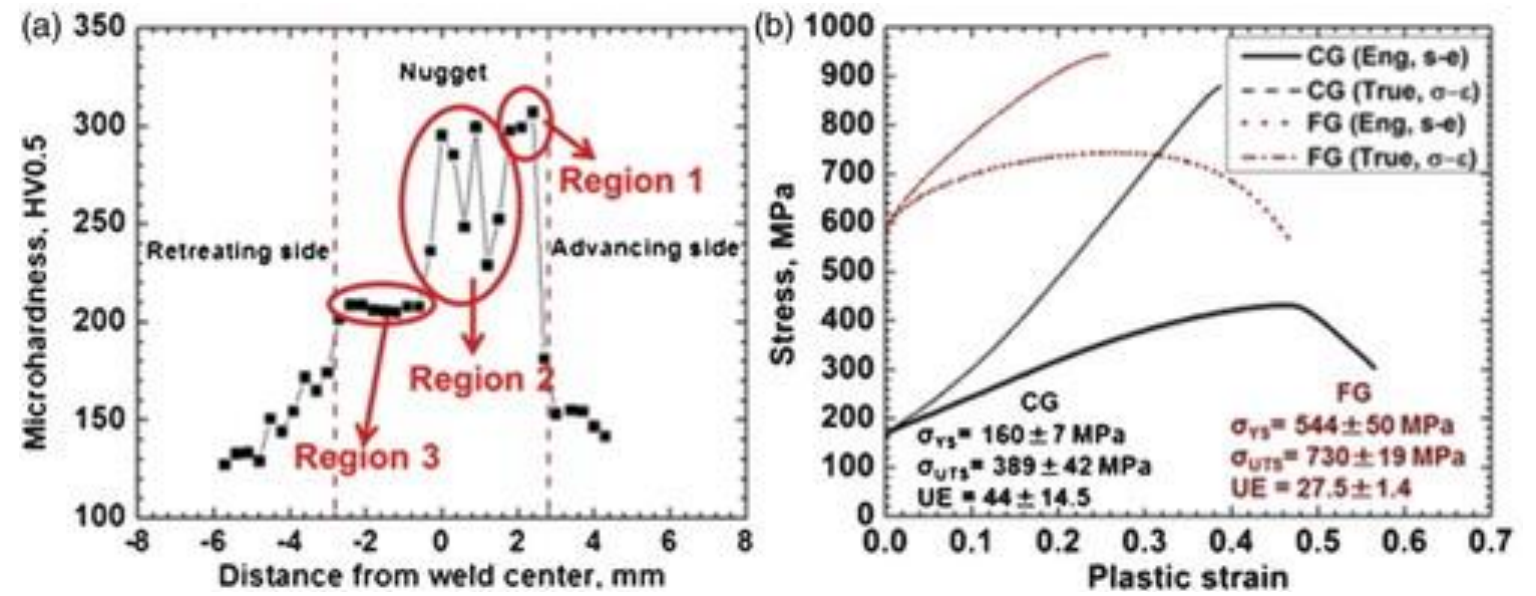

Fig. 9. (a) The variation of hardness across the processed region on the transverse cross section and (b) the plastic stressstrain curves in both CG and FG conditions

Funding: No funding was provided for the manuscript.

Acknowledgments: Author is thankful to his mother Sucheta Mishra for always being a motivation to him.

Conflicts of Interest: The author declares no conflict of interest

\section{References}

[1] Zhang, Yong. (2019). History of High-Entropy Materials. 10.1007/978-981-13-8526-1_1.

[2] Yeh JW, et al. Nanostructured high-entropy alloys with multiple principal elements: novel alloy design concepts and outcomes. Adv. Eng. Mat. 2004; 6:299-303. doi: 10.1002/adem.200300567.

[3] Miracle D. B. (2019). High entropy alloys as a bold step forward in alloy development. Nature communications,10(1),1805. https://doi.org/10.1038/s41467-019-09700-1

[4] Ye, Y.F., Wang, Q., Lu, J., Liu, C.T. and Yang, Y., 2016. High-entropy alloy: challenges and prospects. Materials Today, 19(6), pp.349-362.

[5] Modupeola Dada, Patricia Popoola, Samson Adeosun and Ntombi Mathe (September 27th 2019). High Entropy Alloys for Aerospace Applications [Online First], IntechOpen, DOI: 10.5772/intechopen.84982. Available from: https://www.intechopen.com/online-first/high-entropy-alloys-for-aerospace-applications

[6] Cui, L.; Ma, B.; Feng, S.Q.; Wang, X.L. Microstructure and Mechanical Properties of High-Entropy Alloys CoCrFeNiAl by Welding. Adv. Mater. Res. 2014, 936, 1635-1640. 
[7] Lippold, J.; Kiser, S.; DuPont, J. Welding Metallurgy and Weldability of Nickel-Base Alloys; Wiley: Hoboken, NJ, USA, 2013.

[8] Vendan, S.; Gao, L.; Garg, A.; Kavitha, P.; Dhivyasri, G.; SG, R. Interdisciplinary Treatment to ARC Welding Power Sources; Springer: Singapore, 2018.

[9] Kong, X.; Yang, Q.; Li, B.; Rothwell, G.; English, R.; Ren, X. Numerical study of strengths of spot-welded joints of steel. Mater. Des. 2008, 29, 1554-1561.

[10] Chen, S.; Tong, Y.; Liaw, P. Additive Manufacturing of High-Entropy Alloys: A Review. Entropy 2018, $20,937$.

[11] Baisukhan, A.; Nakkiew, W. Sequential Effects of Deep Rolling and Post-Weld Heat Treatment on Surface Integrity of AA7075-T651 Aluminum Alloy Friction Stir Welding. Materials 2019, 12, 3510.

[12] Park, S., Nam, H., Na, Y. et al. Effect of Initial Grain Size on Friction Stir Weldability for Rolled and Cast CoCrFeMnNi High-Entropy Alloys. Met. Mater. Int. (2019). https://doi.org/10.1007/s12540-019-00466-1

[13] Jo, M., Kim, H., Kang, M. et al. Microstructure and mechanical properties of friction stir welded and laser welded high entropy alloy CrMnFeCoNi. Met. Mater. Int. 24, 73-83 (2018). https://doi.org/10.1007/s12540-017-7248-x

[14] Nene, S.S., Liu, K., Frank, M. et al. Enhanced strength and ductility in a friction stir processing engineered dual phase high entropy alloy. Sci Rep 7, 16167 (2017). https://doi.org/10.1038/s41598-017-16509-9

[15] Komarasamy, M., Kumar, N., Tang, Z., Mishra, R.S. and Liaw, P.K., 2015. Effect of microstructure on the deformation mechanism of friction stir-processed A10. $1 \mathrm{CoCrFeNi}$ high entropy alloy. Materials Research Letters, 3(1), pp.30-34.

[16] Zhu, Z.G., Sun, Y.F., Goh, M.H., Ng, F.L., Nguyen, Q.B., Fujii, H., Nai, S.M.L., Wei, J. and Shek, C.H., 2017. Friction stir welding of a CoCrFeNiAl0. 3 high entropy alloy. Materials Letters, 205, pp.142-144.

[17] Shaysultanov, D., Stepanov, N., Malopheyev, S., Vysotskiy, I., Sanin, V., Mironov, S., Kaibyshev, R., Salishchev, G. and Zherebtsov, S., 2018. Friction stir welding of a carbon-doped CoCrFeNiMn high-entropy alloy. Materials Characterization, 145, pp.353-361.

[18] Rui Xuan Li and Yong Zhang (December 3rd 2018). Entropic Alloys for Cryogenic Applications, Stainless Steels and Alloys, Zoia Duriagina, IntechOpen, DOI: 10.5772/intechopen.82351. Available from: https://www.intechopen.com/books/stainless-steels-and-alloys/entropic-alloys-for-cryogenicapplications

[19] Victor Geanta and Ionelia Voiculescu (October 23rd 2019). Characterization and Testing of High-Entropy Alloys from AlCrFeCoNi System for Military Applications [Online First], IntechOpen, DOI: 10.5772/intechopen.88622. Available from: https://www.intechopen.com/online-first/characterization-and-testing-of-highentropy-alloys-from-alcrfeconi-system-for-military-applications

[20] Ashutosh Sharma (April 6th 2020). High-Entropy Alloys for Micro- and Nanojoining Applications [Online First], IntechOpen, DOI: 10.5772/intechopen.91166. Available from: https://www.intechopen.com/onlinefirst/high-entropy-alloys-for-micro-and-nanojoining-applications

(C) 2021 by the authors. Submitted for possible open access publication under the terms and conditions of the Creative Commons Attribution (CC BY) license (http://creativecommons.org/licenses/by/4.0/). 